\title{
Svangerskapsrelaterte psykiske lidelser: kliniske og epidemiologiske utfordringer
}

\author{
Jan Øystein Berle og Fred Holsten \\ Psykiatrisk Institutt, Universitetet i Bergen, Haukeland Sykehus, 5021 Bergen \\ Korrespondanse til Jan Øystein Berle \\ Telefon: 55974420 (Psykiatrisk Institutt) / 55974429 (direkte kontor) Telefax: 55974419 E-mail: jan.berle@psyk.uib.no
}

\begin{abstract}
SAMMENDRAG
Psykisk sykdom under svangerskapet og i post partum perioden representerer lidelser av varierende alvorlighetsgrad og er av stor betydning for morens velbefinnende, utvikling av mor-barn relasjonen og for familien. På dette feltet er internasjonal forskning betydelig, men resultatene kanskje mindre kjent her i landet. Tilsvarende norske undersøkelser er det få av og behandlingspraksis er høyst varierende. I denne artikkelen gjennomgås kort de mest aktuelle svangerskapsrelaterte psykiske lidelser og noen av deres konsekvenser. Behovet for ny forskning understrekes, og spesielt nevnes de store muligheter som foreligger ved en planlagt nyfødtkohortstudie som over to år tar sikte på å inkludere over 100000 norske fødende kvinner og deres barn. Studien som er bredt anlagt, er initiert av Statens institutt for folkehelse (SIFF) og Medisinsk fødselsregister. Oppstart av studien planlegges i siste halvår av 1997.
\end{abstract}

\section{Berle JØ, Holsten F. Pregnancy related psychiatric disorders. Clinical and epidemiological challenges. Nor J Epidemiol 1997; 7 (1): 111-116.}

\section{ENGLISH SUMMARY}

Pregnancy-related mental disorders represent a major challenge to modern medicine and the society; illness in this period affects not only the mother or mother-to-be, but also the mother-infant relationship and concerns and influences the entire family. A general overview of pregnancy related psychiatric disorders are given. International knowledge and research is considerable. Few studies in this area are published in Norway, and common guidelines for treatment of these conditions are still lacking. There certainly is a potential for improvement both of clinical practice and services in this field in our country. The authors describe a Norwegian national cohort study starting in 1997 planned as a two year prospective study of all women giving birth, in excess of 100000 women. This represents a unique opportunity to conduct a wide range of studies of pregnancy related psychiatric illness both in the cohort as a whole and for selected subgroups.

\section{INNLEDNING}

Psykiske lidelser er i dag den hyppigste og kanskje mest alvorlige komplikasjonen knyttet til kvinners fertile alder, og da særlig under svangerskap og fødsel. De psykologiske mekanismer som settes i gang under svangerskap og ved fødsel er noe av det mest komplekse og gjennomgripende en kvinne opplever i løpet av livet. Når dette finstemte samspillet av aktivitet og interaksjon, emosjonelle reaksjoner og biologiske prosesser ikke fungerer som det skal, kan det oppstå en rekke forskjellige psykiatriske sykdomstilstander. De mest vanlige er unipolare depresjoner, tvangslidelser, panikkangst og andre angstlidelser; samt bipolare affektive lidelser og puerperalpsykoser (1).

Disse lidelsene påvirker i varierende grad kvinnenes omsorgsevne og utviklingen av mor-barn relasjo- nen, og kan i neste omgang påvirke barnas emosjonelle og kognitive utvikling og kvinnenes ekteskapelige forhold. Det som i utgangspunktet antas å være relativt vanlige psykiske lidelser med god behandlingsrespons og god prognose, kan lett overses med kronifisering eller forverring av tilstanden som resultat. Ubehandlet kan noen av disse lidelsene resultere i suicid og i meget sjeldne tilfeller også infanticid.

Vår forståelse av disse lidelsenes relasjon til svangerskap og fødsel er fortsatt ufullstendig og preget av myter, løse antagelser og konklusjoner basert på eldre og ufullstendige studier. Behandlingen som tilbys kan være preget av dette. I vanlig brukte psykiatriske lærebøker er disse problemstillingene fortsatt ofte viet lite oppmerksomhet.

Med en stadig kortere liggetid ved våre fødeavdelinger er det viktig å kartlegge risikofaktorer for at kvinner utvikler psykiske lidelser i svangerskapet og 
puerperiet, slik at kvinner som står i fare for å utvikle slike tilstander så raskt som mulig kan bli identifisert. Behandlingen byr i seg selv på spesielle utfordringer fordi man må ta spesielle hensyn til fosteret under graviditet og det nyfødte barn ved amming (2). Samtidig er det viktig å komme til med rask og effektiv hjelp for å sikre at mor og barn tidlig får etablert de nødvendige følelsesmessige tilknytninger.

\section{PSYKISK SYKDOM UNDER SVANGERSKAPET}

Selv om svangerskapet vanligvis har blitt sett på som en periode med følelsesmessig velvære, har nyere undersøkelser ikke understøttet dette for kvinner med en tidligere sykehistorie med depresjon eller angstlidelse. Mens innleggelsesraten for psykiske lidelser etter fødselen øker med en faktor på 10-20 eller mer, har man ikke funnet tegn til slik økning under svangerskapet (3).

\section{Affektive lidelser under svangerskapet}

Forekomsten av lettere og moderate lidelser i svangerskapet er relativt lite undersøkt. I flere internasjonalt anerkjente undersøkelser har man funnet at raten for depresjoner i svangerskapet ikke er høyere enn hos tilsvarende ikke-gravide kvinner. Cirka $10 \%$ av gravide kvinner utvikler en depresjon, og har kvinnen tidligere hatt depresjoner, øker risikoen for svangerskapsdepresjon (4-6). Andre prediktorer for å utvikle depresjon under svangerskapet er lav sosioøkonomisk status, alkoholisme, mangel på støtte fra partner, ekteskapelige konflikter samt negative livshendelser som kan utløse depresjon hos ellers sårbare individer. Kvinner med bipolare lidelser er ofte lettere og mer stabile i svangerskapet. Med bipolare lidelser forstås manisk depressiv sinnslidelse med både maniske og depressive sykdomsfaser.

\section{Schizofrene sykdomstilstander under svangerskapet}

Det synes ikke å være en økt forekomst av akutte forverrelser av kjente schizofrene tilstander under svangerskapet. Behovet for antipsykotisk medikasjon under graviditet hos pasienter med kjent kronisk schizofren sykdom i kronisk fase representerer imidlertid en ekstra utfordring med viktige avveininger og risikovurderinger. Dette må regnes som risikosvangerskap og krever spesialistoppfølging.

\section{Panikkangst og tvangslidelser under svangerskapet}

Hormonelle endringer i svangerskapet kan ha en anxiolytisk effekt, og det sympatiske nervesystem er mindre aktivt i denne perioden. Mange kvinner med panikkangst sier at svangerskapet er deres beste periode, mens andre ikke merker noen forskjell. I de fleste undersøkelser er det få som sier at de blir verre (7). Noen kvinner kan rapportere at deres tvangssymptomer blir verre, eller debuterer i svangerskapet (8).

\section{PSYKISK SYKDOM I POSTPARTUM PERIODEN}

\section{Affektive lidelser i postpartum perioden}

Det er stor forskjell i sårbarhet, og depresjoner etter fødselen varierer fra lette "postpartum blues" til dramatiske og akutt innsettende psykotiske depresjoner. Man skiller vanligvis mellom tre alvorlighetsgrader av affektive symptomer i tiden etter fødselen: Postpartum blues, moderate til alvorlige depresjoner og postpartum (puerperal) psykoser.

"Postpartum blues" er et vanlig syndrom som vikler seg i løpet av de første 7-10 dagene etter en fødsel. Tilstanden er karakterisert ved emosjonell labilitet, gråtetokter, tristhet og noen ganger søvnvansker og grader av subjektiv opplevelse av konfusjon. Tilstanden utvikler seg raskt og kan forekomme allerede fra første dag etter fødselen, men vanligvis er symptomene mest uttalt mellom 3. og 7. dag. Mellom 50 og $80 \%$ av alle kvinner får i varierende grad en slik reaksjon etter fødsel, og tilstanden betraktes som et normalfenomen (9). Dette kan imidlertid føre til at man blir mindre observant på de mer alvorlige depresjonene, slik at disse lettere overses eller bortforklares som normalreaksjoner. Den viktigste terapeutiske intervensjon ved postpartum blues er å avvente, gi trygghet og søke å fange opp de kvinnene som utvikler behandlingstrengende depresjoner. Kvinner med premenstruelt syndrom er mer utsatt for disse reaksjonene, og de er hyppigst forekommende etter første fødsel.

Flere epidemiologiske studier gjort de senere år viser at hos fra $9 \%$ til $15 \%$ av kvinner som føder, oppstår det en klinisk depresjon etter fødselen. Av studier foretatt av postnatal depresjon, er det meget få som angir under $10 \%$ forekomst, mens enkelte angir tall over 20\% (1). Det er gjort studier i England som viser at henvisning til psykiater ved slike sykdomstilstander kun skjer hos rundt 3\% (10). Dette er et paradoks. Noe kan skyldes at allmennleger behandler tilstandene, men det er nærliggende å mistenke underdiagnostisering og underbehandling av disse lidelsene. Det er omdiskutert om det er økning i forekomst av upsykotiske depresjoner post partum (1). En prospektiv studie anslår forekomsten av psykisk sykdom i året etter fødsel til 15\%, en vesentlig del er depresjoner - men beskriver nesten tilsvarende forekomst hos kvinner som ikke har født (11).

Flere forfattere peker på en betydelig underdiagnostisering av de moderate depresjonstilstander post partum. Negative effekter av postnatal depresjon på barnets kognitive og emosjonelle utvikling og på morbarn relasjonen er relativt godt dokumentert (12-20). Selv om de fleste av de moderate depresjonene glir over i løpet av de første tre måneder, er kronifiseringsrisikoen betydelig og mer enn et års sykdomsvarighet beskrives hyppig $(11,21,22)$. Postnatal depresjon kan ha sterke negative effekter på kvinnens ekteskapelige relasjoner (23-25). Viktige prediktive 
faktorer synes å være tidligere puerperal depresjon, tidligere aborter eller dødfødsler, depresjon under svangerskapet, ytre belastninger etter fødselen, samt alvorlige tilfeller av postpartum blues (10).

Psykotiske tilstander etter fødsel forekommer langt sjeldnere enn postpartum depresjoner, anslagsvis et sykdomstilfelle per 500 til 2000 fødsler (1). Flere anerkjente tidligere studier, deriblant en norsk, har vist at postpartum psykose er nært forbundet med bipolar sykdom $(26,27)$. Nyere studier konkluderer også med at post partum psykosene oftest er affektive i sin natur (9). Kvinner med sykehistorie med alvorlig affektiv lidelse av bipolar type eller av schizoaffektiv natur har en sterkt forøket risiko for å utvikle nye sykdomsepisoder, og hele $51 \%$ utvikler en ny sykdomsepisode innen de 6 første månedene etter fødsel (28). Kvinner med kjent bipolar lidelse har en øket risiko for å utvikle en mer dramatisk form for lidelsen etter fødsel (29). Profylaktisk behandling av disse kvinnene etter fødsel er derfor svært viktig (30). De fleste utvikler tilstanden innen tre uker etter fødsel og noen frembyr også lettere symptomer under svangerskapet. Hos enkelte starter tilstanden som en "postpartum blues" eller en depresjon og utvikler seg videre til en psykotisk affektiv tilstand. De mest dominerende risikofaktorer synes å være tidligere psykisk lidelse, spesielt bipolar lidelse, samt sterk slektsbelastning av affektiv lidelse.

I noen få studier har man sammenlignet psykoser som starter tidlig i postpartumperioden (innen to uker etter forløsning) med andre psykoser. Postpartum psykosene hadde mer forvirringspreg og mer uttalte maniske symptomer, mens ikke-postpartum psykosene hadde flere schizofrene symptomer. Dette kan bety at postpartum psykoser representerer en distinkt gruppe relatert til bipolar sykdom, men dette må studeres nærmere (31).

Behandlingen av postpartum psykosene og de alvorlige depresjonene postpartum er den samme som for alvorlige affektive lidelser generelt, bortsett fra at ECT (elektrostimuleringsbehandling) synes spesielt effektivt og derfor oftere blir brukt her, vanligvis med rask effekt og lite bivirkninger $(1,32,33)$. Hurtig behandling er kanskje viktigere i puerperiet enn i noen annen fase av livet. Det anbefales at pasienter med risikofaktorer følges spesielt nøye de første fire til åtte ukene etter fødselen.

Både depresjonene og psykosene i post partum perioden kan gi alvorlige konsekvenser for kvinnene som rammes, for deres barn og familier. Tilstandene vil i varierende grad influere på kvinnenes omsorgsevne og evne til å fungere $(15,18)$. I alvorlige tilfeller kan selvbeskadigelse og omsorgssvikt forekomme (1). Mens psykosene i seg selv sjelden forblir udiagnostiserte, knyttes de ikke til at mor har født fordi det ikke finnes noen egen diagnostisk kategori for postpartum psykoser. Det er mer vanlig at moderate depresjoner i post-partum perioden forblir udiagnostiserte eller blir diagnostisert sent og behandlet ufull- stendig, med betydelig risiko for lang tids dysfungering og kronifisering som resultat. For postpartum psykosene har man spesielt lurt på om en psykotisk tilstand hos mor i løpet av barnets første måneder av livet ville ha negative konsekvenser for barnets mentale utvikling. Noe overraskende viser en nyere undersøkelse fra Sverige hvor barna ble fulgt opp over en periode på 6 år, ikke holdepunkter for dette (34).

\section{Tvangslidelser, panikkangst og andre angstlidelser i postpartum perioden}

Mens mange studier har beskrevet puerperalperioden som en fase i kvinnens liv med øket risiko for depresjoner og psykoser, er det mindre kjent om risiko for utvikling av andre sykdomsgrupper som panikklidelse, andre angstlidelser og tvangslidelser (OCD) i postpartum perioden $ø \mathrm{ker}$. To studier beskriver $ø \mathrm{kt}$ risiko for OCD i puerperalperioden $(8,35)$. For lite oppmerksomhet på disse tilstandene slik at de ikke blir diagnostisert og behandlet, kan ha alvorlige konsekvenser såvel for pasienten som for hennes familie.

\section{Schizofrenier i postpartum perioden}

Forverrelse i postpartum perioden av kjente schizofrene tilstander er vanlig, men utgjør et mindretall av disse psykosene. I de fleste studiene utgjør schizofreniene mellom $2 \%$ og $16 \%$ av postpartum psykosene (32).

\section{SAMMENLIGNING AV PSYKISK SYKDOM I SVANGERSKAP OG POSTPARTUM}

To anerkjente undersøkelser $(36,37)$ synes klart å tyde på lavere hyppighet av psykoser under svangerskap enn etter, og det foreligger tallrike studier som angir det samme. Man har ikke funnet holdepunkter for økt antall psykoser mot slutten av svangerskapet (3), men det foreligger rapporter om kvinner som blir "abnormally excited" siste svangerskapsmåned og som siden utvikler mani (38). Personer med bipolare lidelser, det vil si lidelser preget av depresjoner og perioder med oppstemthet eller manier, har ofte en bedre og mer stabil periode i svangerskapet, mens de har en sterkt øket risiko for tilbakefall etter fødsel $(3,28,30,39)$. Det finnes laboratoriedata om at depresjoner begrenset til puerperalperioden karakteriseres ved lenger og mer intens REM-søvn aktivitet enn ved andre depresjoner (40).

Risiko for sykehusinnleggelse grunnet psykisk sykdom er redusert i svangerskapet for ikke-psykotisk lidelse. Dette er spesielt godt vist $i$ en omfattende studie fra Edinburgh som omfattet 54087 fødsler. En registrerte antall sykehusinnleggelser pr. måned og fant $8 /$ mnd før svangerskap, $5 /$ mnd under svangerskap og 17/mnd i første postpartum måned, 14/mnd i annen, $10 \mathrm{i}$ tredje og $9 / \mathrm{mnd}$ deretter. For psykoser var antallet $2,1 / \mathrm{mnd}$ før inntrådt graviditet, 2,0 under svangerskap, 51 i første måned postpartum, $25 \mathrm{i}$ annen måned postpartum og $13 \mathrm{i}$ tredje måned post- 
partum og 4/mnd deretter. Edinburgh-studien viser at risikoen for å utvikle psykose første måned post partum sammenlignet med jevnaldrende kvinner som ikke har født er 21,7 ganger større og for førstegangsfødende hele 35 ganger større (3). Selv om den absolutte risiko for utvikling av psykose postpartum fortsatt er lav, så er den høyere etter fødsel enn på noe annet tidspunkt i livet. Økningen i sykdomshyppighet postpartum er også vesentlig større for psykoser enn for upsykotiske depresjoner $(1,11)$.

Det er klart dokumentert, blant annet i en norsk kohortstudie av nesten 1 million kvinner som ble fulgt i 15 år, at selvmordsraten er lavere hos kvinner som har født barn (41). Studien omtaler imidlertid ikke postpartum perioden spesielt og må ikke føre til at man feilaktig neglisjerer suicidalfaren ved fødselsdepresjoner og puerperalpsykoser.

\section{SYKEHUSINNLEGGELSE AV MOR OG BARN}

Tradisjonelt har det vært lite vanlig å la mor ha med seg spebarnet når hun blir alvorlig psykisk syk og må hospitaliseres etter fødselen. I Norge har vi ingen god oversikt over hvor ofte dette skjer. I England har man opprettet enkelte spesialavdelinger tilrettelagt for dette, samt dagtilbud for mor-barn. I behandlingen legger en vekt på familietilnærming med spesielt fokus på hvorledes den emosjonelle kontakten mellom mor og barn fungerer (1). En driver også konsulentvirksomhet om svangerskapsrelaterte psykiske lidelser i forhold til andre deler av helsevesenet. Selv om det har vært en viss tradisjon rundt i verden for ikke å atskille foreldre og barn ved innleggelse på pediatriske sykehus, er det mindre vanlig å holde mor og spebarn sammen når mor får en psykisk lidelse. Farene ved å skille et lite barn fra mor er tidligere beskrevet av flere forfattere, her kan spesielt nevnes Bowlby (42) og Brockington (1).

\section{SVANGERSKAPS- OG HELSEKONTROLLER}

I ukene etter fødselen bør man være meget oppmerksom på kvinnenes mentale tilstand. En del av svangerskapskontrollen bør også omfatte den gravide kvinnens mentale helsetilstand. Psykisk ustabilitet eller neurovegetative symptomer kan være tegn på at kvinnen kan utvikle alvorlige postpartum lidelser. Affektivt velvære og lykke umiddelbart etter fødsel er i seg selv ikke noen god prediktor for utviklingen i ukene som følger. Ved helsekontroller av spebarn bør man altså i større grad også fokusere på morens mentale helse.

Et nyttig screeninginstrument for postpartum depresjon som er utviklet og i omfattende bruk $i$ England er Edinburgh Postnatal Depression Scale (EPDS). Dette er en 10-punkts selvutfyllingsskala spesielt utformet for å kunne brukes i allmennpraksis og på helsestasjoner (43). Denne er blitt validert $\mathrm{i}$ England $(43,44)$, i Australia $(45)$, i Sverige $(46,47)$ og i Portugal (48). EPDS er også oversatt til hollandsk
(49) og islandsk (50). Instrumentet er nå nærmest et standardinstrument ved psykiatriske studier av postpartum depresjoner. Ved Universitetet i Bergen arbeider man nå med å oversette og prøve ut EPDS under norske forhold.

\section{"BØR JEG FÅ FLERE BARN, DOKTOR?"}

En tidligere episode av depresjon, bipolar lidelse, angstlidelse eller tvangslidelse i postpartumperioden øker risikoen for nye sykdomsepisoder postpartum. En klassisk norsk studie viste at hos enkelte er episodene alltid svangerskapsrelaterte (26). Funnet er siden bekreftet av flere andre (1). Hos de fleste vil en postpartum episode av sykdom bety øket risiko for nye sykdomsepisoder også i andre livsfaser. Vi trenger nye og bedre studier for å få mer pålitelig kunnskap om sammenhengen mellom slike lidelser før og etter fødsel, og vi trenger å vite mer om sårbarheten for tilbakefall etter en sykdomsepisode. Dette har stor betydning både for forebyggende helsearbeid og for å utvikle nye strategier for profylaktisk behandling.

Mødre som har hatt psykisk lidelse postpartum har større risiko for å få slik sykdom igjen etter senere fødsler. Vi trenger bedre kartlegging av prognostiske faktorer som er viktige for å kunne gi bedre råd i slike sammenhenger. Det er mulig at psykiske lidelser som utløses eller oppstår i postpartumperioden atskiller seg noe fra tilsvarende lidelser som utløses i andre livsavsnitt både når det gjelder sårbarhetsfaktorer, symptombilde, behandlingsrespons og prognostiske faktorer $(1,21,22)$. Dette vet vi ikke nok om.

\section{KOHORTSTUDIE AV MOR OG BARN}

I Norge planlegger man å gjøre en kohortundersøkelse over to år med start i 1997 der man inviterer alle kvinner som føder til å delta. Undersøkelsen er omfattende og skal være en basis for epidemiologisk forskning gjennom en nasjonal oppfølging av gravide og nyfødte. En håper på inklusjon av mellom 100000 og 120000 kvinner med deres barn. En tilsvarende undersøkelse er under planlegging i Danmark. En rekke underprosjekt er planlagt i tilslutning til denne kohortstudien, men flere psykiatriske prosjekt er ønskelig. Kohortstudien gir et vell av muligheter til å studerer mødrenes psykiske helse i forhold til de øvrige parametre som registreres. Slike data kan være av uvurderlig betydning ved senere studier av disse kvinnenes psykiske helse videre samt barnas utvikling. Gode studier her vil kunne gi omfattende kunnskaper om disse helt sentrale fasene i et barns, morens og familiens liv. Denne muligheten bør utnyttes.

\section{KONKLUSJON}

Klinisk representerer svangerskapsrelaterte psykiske lidelser store utfordringer. Forekomsten av psykoser etter svangerskap er sterkt forhøyet. Det er mer 
usikkert om det er noen økning av behandlingstrengende depresjoner etter fødsel. Vi trenger derfor flere undersøkelser av dette. Ubehandlet vil disse tilstandene kunne gi alvorlige konsekvenser for mor, for barn og for samholdet i familien. Enkelte undersøkelser synes å tyde på at om disse tilstandene forblir ubehandlet, kan det være skadelig for barnas utvikling.

Epidemiologisk forskning i Norge kan hjelpe oss til å kartlegge psykiske lidelser i svangerskap og etter fødsel, og om forekomsten av disse endrer seg i pakt med befolkningens livsbetingelser. Det er spesielt behov for studier som går ut over kun å kartlegge forekomst av depresjoner og psykoser. Mye tyder på at ved de psykotiske postpartum lidelsene har biologiske faktorer stor betydning. Ved de ikke-psykotiske tilstandene antas årsakene å være mer sammensatte, og man trenger derfor en bedre kartlegging av sosiale, økonomiske, miljømessige, psykologiske og biologis- ke faktorers relative betydning. Kohortstudien gir en unik mulighet for dette. Epidemiologisk forskning kan også hjelpe oss å kartlegge om det er en endret forekomst av andre psykiske lidelser relatert til svangerskap og fødsel. Det er mulig at mer planmessige studier må til for å avdekke den reelle forekomsten av disse tilstandene, som kanskje ellers lett blir overdøvet av barnegråt.

Den planlagte kohortstudien vil også gjøre det mulig å få bedre data på om psykisk sykdom hos mor etter fødsel påvirker barnets senere utvikling. Vi tror at en større bevissthet om psykiske lidelser i kvinners fertile alder også vil kunne bedre forebyggelsen av sviktende mor-barn kontakt, avvisningsproblematikk og barnemishandling. Med de kunnskaper man har i dag, vil det være mulig å gi rask og effektiv hjelp ved de fleste av disse tilstandene hvis de blir oppdaget og får korrekt behandling.

\section{REFERANSER}

1. Brockington IF. Motherhood and Mental Health. Oxford: Oxford University Press, 1996.

2. Wisner KL, Perel JM, Findling RL. Antidepressant treatment during breast-feeding. Am J Psychiatry 1996; 153: $1132-1137$.

3. Kendell RE, Chalmers JC, Platz C. Epidemiology of puerperal psychoses. Br J Psychiatry 1987; 150: 662673.

4. O'Hara MW, Neunaber DJ, Zekoski EM. Prospective study of postpartum depression: prevalence, course and predictive factors. J Abnorm Psychol 1984; 93: 158-171.

5. O'Hara MW. Social support, life events and depression during pregnancy and the puerperium. Arch Gen Psychiatry 1986; 43: 569-573.

6. Altshuler LL, Szuba MP. Course of psychiatric disorders in pregnancy: Dilemma in pharmacologic management. Neurol Clin 1994; 12: 613-635.

7. Neziroglu F, Anemone R, Yaryura-Tobias JA. Onset of obsessive-compulsive disorder in pregnancy. Am J Psychiatry 1992; 149: 947-950.

8. Buttolph ML, Holland A. Obsessive compulsive disorders in pregnancy and childbirth. In: Jenike M, Baer L, Minichiello WE, eds. Obsessive Compulsive Disorders, Theory and Management. Chicago: Yearbook Medical Publishers, 1990.

9. Gitlin MJ, Pasnau RO. Psychiatric syndromes linked to reproductive function in women: A review of current knowledge. Am J Psychiatry 1989; 146: 1413-1422.

10. Playfair HR, Gowers JI. Depression following childbirth - a search for predictive signs. J R Coll Gen Pract 1981; 31: 201-208.

11. Cooper PJ, Campbell EA, Day A, Kennerley H, Bond A. Non-psychotic psychiatric disorder after childbirth: A prospective study of prevalence, incidence, course and nature. Br J Psychiatry 1988; 152: 799-806.

12. Cogill SR, Caplan HL, Alexandra H, Robson KM. Impact of maternal postnatal depression on cognitive development of young children. Br Med J 1986; 292: 1165-1167.

13. Stein A, Gath DH, Bucher J, Bond A, Day A, Cooper PJ. The relationship between postnatal depression and mother-child interaction. Br J Psychiatry 1991; 158: 46-52.

14. Murray RM, Stein A. The effects of postnatal depression on the infant. Baillière's Clin Obstet Gynaecol 1989; 3: $921-933$.

15. Murray RM, Cooper PJ, Stein A. Postnatal depression and infant development. Br Med J 1991; 302: 978-979.

16. Richman N, Stevenson JE, Graham PJ. Prevalence of behavioural problems in three year old children: An epidemiological study in a London borough. $J$ Child Psychol Psychiatry 1975; 17: 75-78.

17. Weissman MM, Paykel ES, Klerman GL. The depressed woman as a mother. Soc Psychiatry 1972; 7: 98-108.

18. Ghodsian M, Zajicek E, Wolkind S. A longitudinal study of maternal depression and child behaviour problems. J Child Psychol Psychiatry 1984; 25: 91-109.

19. Wrate RM, Rooney AC, Thomas PF, Cox JL. Postnatal depression and child development. A three-year follow-up study. Br J Psychiatry 1985; 146: 622-627.

20. Rutter M, Quinton D. Parental psychiatric disorder: Effects on children. Psychol Med 1984; 14: 853-880. 
21. Pitt B. Atypical depression following childbirth. Br J Psychiatry 1968; 114: 1325-1335.

22. Nott PN. Extent, timing and persistence of emotional disorders following childbirth. Br J Psychiatry 1987; 151: 523-527.

23. Boyce P. Personality dysfunction, marital problems and postnatal depression. In: Cox J, Holden J, ed. Perinatal psychiatry: use and misuse of the Edinburgh Postnatal Depression Scale. London: Gaskell, 1994: 82-103.

24. Cox JL, Connor Y, Kendell RE. Prospective study of the psychiatric disorders of childbirth. Br J Psychiatry 1982; 140: 111-117.

25. O'Hara MW, Zekoski EM, Phillips LH, et al. A controlled prospective study of postpartum mood disorders: comparison of childbearing and nonchildbearing women. J Abnorm Psychol 1990; 99: 3-15.

26. Bratfos O, Haug JO. Puerperal mental disorders in manic-depressive females. Acta Psychiatr Scand 1966; 42: 285-294.

27. Reich T, Winokur G. Postpartum psychoses in patients with manic depressive disease. J Nerv Ment Dis 1970; 151: 60-68.

28. Marks MN, Wieck A, Checkley SA, Kumar R. Contribution of psychological and social factors to psychotic and non-psychotic relapse after childbirth in women with previous histories of affective disorder. $J$ Affect Disord 1992; 29: 253-264.

29. Brockington IF, Cernik KF, Schofield EM, Downing AR, Francis AF, Keelan C. Puerperal psychosis, phenomena and diagnosis. Arch Gen Psychiatry 1981; 38: 829-833.

30. Cohen LS, Sichel DA, Robertson LM, Heckscher E, Rosenbaum JF. Postpartum prophylaxis for women with bipolar disorder. Am J Psychiatry 1995; 152: 1641-1645.

31. Brockington IF, Margison FR, Schofield E, Knight RJE. The clinical picture of the depressed form of puerperal psychosis. J Affect Disord 1988; 15: 29-37.

32. Harding JH. Postpartum psychiatric disorders: A review. Compr Psychiatry 1989; 30: 109-11.

33. Oates MR. The treatment of psychiatric disorders in pregnancy and the puerperium. Clin Obstet Gynecol 1986; 13: 385-395.

34. McNeil TF, Persson-Blennow I, Binett B, Harty B, Karyd UB. A prospective study of postpartum psychoses in a high-risk group. Relationship to later offspring characteristics. Acta Psychiatr Scand 1988; 78: 613-617.

35. Sichel DA, Cohen LS, Dimmock JA, Rosenbaum JF. Postpartum obsessive compulsive disorder: A case series. J Clin Psychiatry 1993; 54: 156-159.

36. Paffenbarger RS Jr. Epidemiological aspects of mental illness associated with childbearing. In: Brockington IF, Kumar R, eds. Motherhood and mental Illness. London: Academic Press, 1982.

37. Kendell RE, Wainwright S, Hailey A, Shannon B. The influence of childbirth on psychiatric morbidity. Psychol Med 1976; 6: 297-302.

38. Mc Neil TF , Kaij L, Malmquist-Larsson A. Women with nonorganic psychosis: mental disturbance during pregnancy. Acta Psychiatr Scand 1984; 70: 127-139.

39. Kastrup M, Lier L, Rafaelsen OJ. Psychiatric illness in relation to pregnancy and child-birth. Methodologic considerations. Nord Psychiatr Tidsskr 1989; 43: 531-534.

40. Frank E, Kupfer DJ, Jacob M, Blumenthal SJ, Jarrett DB. Pregnancy-related affective episodes among women with recurrent depression. Am J Psychiatry 1987; 144: 288-293.

41. Høyer G, Lund E. Suicide among women related to number of children in marriage. Arch Gen Psychiatry 1993; 50: 134-137.

42. Bowlby J. Child Care and the Growth of Love. London: Pelican, 1953.

43. Cox JL, Holden JM, Sagovsky R. Detection of postnatal depression: Development of the ten-item Edinburgh Postnatal Depression Scale. Br J Psychiatry 1987; 150: 782-786.

44. Murray L, Carothers AD. The validation of the Edinburgh Postnatal Depression Scale on a community sample. Br J Psychiatry 1990; 157: 288-290.

45. Boyce P, Stubbs J, Todd A. The Edinburgh Postnatal Depression Scale: validation for an Australian sample. Aust NZ J Psychiatry 1993; 27: 472-476.

46. Lundh W, Gyllang C. Use of the Edinburgh Postnatal Depression Scale in some Swedish child health care centers. Scand J Caring Sci 1993; 7: 149-154.

47. Wickberg B, Hwang CP. The Edinburgh Postnatal Depression Scale: validation on a Swedish community sample. Acta Psychiatr Scand 1996; 94: 181-184.

48. Areias MEG, Kumar R, Barros H, Figueiredo E. Comparative incidence of depression in women and men, during pregnancy and after childbirth. Validation of the Edinburgh Postnatal Depression Scale in Portugese mothers. Br J Psychiatry 1996; 169: 30-35.

49. Pop VJ, Komproe IH, van Son MJ. Characteristics of the Edinburgh postnatal depression scale in the Netherlands. J Affect Disord 1992; 26: 105-110.

50. Thome M. Screening of postpartum depression by community nurses in Iceland. Address to the 5th Conference of the Marcé Society, York, 4.-7. september 1990. 